\title{
Bioceramics for Tissue Engineering Applications - A Review
}

\author{
Sunho $\mathrm{Oh}^{1}$, Namsik $\mathrm{Oh}^{2}$, Mark Appleford ${ }^{1}$, Joo L. Ong ${ }^{1}$ \\ ${ }^{1}$ The University of Tennessee Health Science Center, Memphis, TN 38163, U.S.A. \\ ${ }^{2}$ Inha University, Incheon, South Korea
}

\begin{abstract}
Three dimensional (3-D) scaffolds have been explored in an attempt to persuade the body to heal or repair tissues that do not do so spontaneously. Considerable advances in tissue engineering and regeneration have been accomplished over the last decade. However, the material and 3-D scaffolds ideal for optimal regeneration of missing or lost tissues has not been identified. While current materials and techniques have met with varying successes, each exhibits limitations that must be addressed. In addition, despite the large amount of research in the area of 3-D scaffolds for bone tissue engineering that has been performed over the past decade, there is an overall lack of success in bringing this technology to the clinic, especially for porous scaffolds used to restore large bone defects. This review paper will focus on the use of calcium phosphate $(\mathrm{CaP})$ materials used for tissue engineering, the different known methods of scaffold synthesis, and some of the significant in vitro, in vivo, and clinical outcomes when these $\mathrm{CaP}$ scaffolds were used in patients.
\end{abstract}

Key words: Calcium phosphate scaffold, bone tissue engineering, bioceramics, nano-coating

\section{INTRODUCTION}

Over 8 million surgical procedures are performed annually in the United States to treat the millions of Americans experiencing organ failure or tissue loss ${ }^{[1]}$. Although the procedures for organ transplantation and reconstruction surgery improve the quality of life, and in some cases save life, there are problems associated with them. In most cases these procedures require either organ donation from a donor individual or tissue transplantation from a second surgical site in the individual being treated. The major problem with organ transplantation is that there exists a drastic shortage of donor organs. In 1996 alone, only 20,000 donor organs were available for 50,000 patients in need. In fact, patients are more likely to die while waiting for a human donor heart than in the first two years after transplantation $^{[1]}$. The problem with second site surgeries is that these procedures are associated with pain and morbidity. As a result of these problems, the science of tissue engineering has emerged with the goal of developing organs, tissues, and synthetic materials outside of the body ready for future transplant use ${ }^{[1-8]}$. The estimated market for future tissue engineered products is approximately $\$ 5$ billion worldwide ${ }^{[2]}$.

In bone defect reconstruction caused by benign tumor or trauma, the use of autologous and allograft bone have been popularly used in clinics ${ }^{[9-12]}$. However use of autologous bone is known to result in secondary trauma and allograft bone induces immune repulsion. In addition, since bone grafts are avascular and are dependent on diffusion, the use of autologous and allograft bones are limited by the size of the defect and the viability of the host vascular bed. It was reported that grafts in large defects were resorbed by the body before the completion of osteogenesis ${ }^{[13,14]}$. To solve these problems, many researches have focused on the use of artificial bone-like materials such as bone cements and bioglass ${ }^{[15-20]}$. However, since bone cements are prepared in the operating room, they are therefore susceptible to infection.

In an attempt to solve some of the problems associated with the use of autologous bone, allograft, and bone cements, the advent of tissue engineering has become a major area of medical research as the search continues to develop better materials to replace lost or missing tissues from the human body ${ }^{[21-22]}$. Although scaffolds for use in guided tissue regeneration and tissue engineering have been the subject of much research over the last decade ${ }^{[23]}$, material selection and the ideal three-dimensional (3-D) scaffold architecture for optimal regeneration of missing or lost tissues has yet to be identified. While current materials and techniques have met with varying successes, each exhibits limitations that must be addressed. In addition, despite the large amount of research in the area of 3-D porous scaffolds for bone tissue engineering that has been performed over the past decade, there is an overall lack of success in bringing this technology to the clinic, especially for use in restoring large bone defects ${ }^{[3-8]}$.

Like any implanted biomaterials, the ideal scaffold should exhibit biocompatibility without causing an inflammatory response or foreign body/toxic reaction. Strong bonding with the host bone, active bone ingrowth into the graft, and bioabsorbability are equally desirable. Although scaffolds can be constructed from 
numerous materials, the primary materials studied mostly revolve around different polymers such as polylactic $\operatorname{acid}^{[24,}{ }^{25]}$, polyglycolic $\operatorname{acid}^{[26]}$, polyurethane ${ }^{[27]}$, and a number of copolymers ${ }^{[28-30]}$. Other polymeric materials studied included polyanhydrides, polyorthoesters, polycaprolactones, polycarbonates, and polyfumarates. These polymers have been used in research for applications in orthopedics, implantable drug delivery systems, intraluminal grafts, stent-like devices, temporary vascular grafts, temporary conduits for peripheral nerve regeneration, and as scaffolds for artificial skin ${ }^{[26]}$. Although the use of biodegradable polymers for the fabrication of porous scaffolds have shown some success in terms to tissue ingrowth, the porous polymeric scaffolds lack sufficient mechanical strength to withstand mechanical loading in areas of load bearing. Aside from insufficient mechanical strength, other problems with biodegradable polymers have included the presence of hydrophobic surfaces and the lowering of localized $\mathrm{pH}$ which are detrimental to tissue formation as a result of the autocatalytic ester breakdown resulting in degradation ${ }^{[24,26,31-37]}$.

In addition to polymeric materials, researchers have also focused on the use of calcium phosphate (CaP) ceramics to synthesize bone-like scaffolds. Rationales for the use of $\mathrm{CaP}$ ceramics stem from the fact that $\mathrm{CaP}$ is found in the body and that it shows promises of biocompatibility, osteoconductivity, and biodegradability. At present, $\mathrm{CaP}$ ceramics such as hydroxyapatite (HA) produced from corals has been reportedly used for orthopedic bone defect reconstruction. These porous coral HA scaffolds are reported to exhibit a hydrothermal exchange reaction thereby converting porous coralline skeletal materials into HA that have similar microstructure as the starting carbonate skeletal material $^{[38]}$. However, the major drawback for the use of coralline HA is the inability to control the pore size and chemical composition, thereby resulting in unpredictable outcomes. In order to take advantage of the biocompatibility of $\mathrm{CaP}$, numerous researchers have turned their attention to the use of synthetic $\mathrm{CaP}$ ceramics in order to engineer trabecular bone-like scaffolds ${ }^{[38-40]}$. This review paper will focus on the use of CaP materials used for tissue engineering, the different methods of scaffold synthesis, and some of the significant in vitro, in vivo, and clinical outcomes when these $\mathrm{CaP}$ scaffolds were used in patients.

\section{SCAFFOLD MATERIALS}

The absorbable, inorganic materials that have been investigated for bone tissue engineering include $\mathrm{CaCO}_{3}$ (argonite), $\mathrm{CaSO}_{4}-2 \mathrm{H}_{2} \mathrm{O}$ (plaster of Paris), and $\mathrm{Ca}_{3}\left(\mathrm{PO}_{4}\right)_{2}$ (beta-whitlockite, a form of tricalcium phosphate, TCP $)^{[41]}$. The most widely studied $\mathrm{CaP}$ ceramics are TCP, HA $\left(\mathrm{Ca}_{10}\left(\mathrm{PO}_{4}\right)_{6}(\mathrm{OH})_{2}\right)$, and tetracalcium phosphate ${ }^{[41,42]}$. The appeal of $\mathrm{CaP}$ rests largely with their biocompatibility. Since they are protein free, minimal immunologic or foreign body reactions have been reported with their use and these materials can be processed to avoid systemic toxicity. Although these inorganic ceramics are not osteoinductive, they are osteoconductive in addition to their remarkable ability to bind directly to bone ${ }^{[41,43]}$.

\section{SCAFFOLD SYNTHESIS}

Many fabrication techniques are available to produce ceramic scaffolds with varying architectural features. These include gas foaming, soluble or volatile poragen processing ${ }^{[44,45]}$, phase-mixing ${ }^{[46]}$, free form fabrication such as strereolithography ${ }^{[47]}$, and template coating and casting ${ }^{[48-51]}$. The first three methods are linked with higher material density with corresponding mechanical strength and offer excellent definition of pore shape. The latter two methods offer improved control over the scaffold architecture with free form fabrication and the advances in selective sintering, an internal architecture of nearly any shape is possible. Liquid sponge coating is limited to the original template used and is likewise formable into any shape. Both of the latter techniques can be used for open-pore architectures with full interconnectivity. The use of ceramic processing has also been reported to advance the developments in photopolymerizable biopolymers. Garg et al. employed stereolithography technology to fabricate ceramic scaffolds using a concentrated colloidal dispersion in an aqueous photocurable polymer solution ${ }^{[52]}$. This has potential for controlling pore size and porosity for precision fabrication of templates or scaffolds.

With template coatings, highly porous microcrystalline $\mathrm{CaP}$ scaffolds can be prepared by applying the CaP slurry with a compression/release process and thereby forming a uniform surface coating on the template. Following a heat-sintering schedule, the templates are volatilized leaving the sintered ceramic scaffold with controllable crystalline structure. Figure 1 shows SEM micrographs of micro- and nanocrystalline HA surfaces with nano-surfaces prepared by the sol-template coating technique.

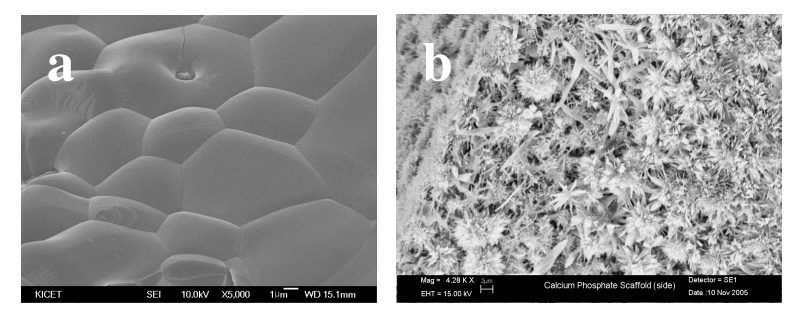

Fig. 1: Scanning electron micrographs of (a) microcrystalline and (b) nano-HA surface.

Analysis of typical template formed scaffolds revealed an average porosity range between 70 to $90 \%$. SEM images from micro- and nano-engineered HA scaffolds 
are shown in Fig. 2 with $90 \%$ porosity as measured by micro-CT and an average pore size of $400 \mu \mathrm{m}$ measured by SEM. Also shown in Fig. 2, an ideal scaffold is fully inter-connective.
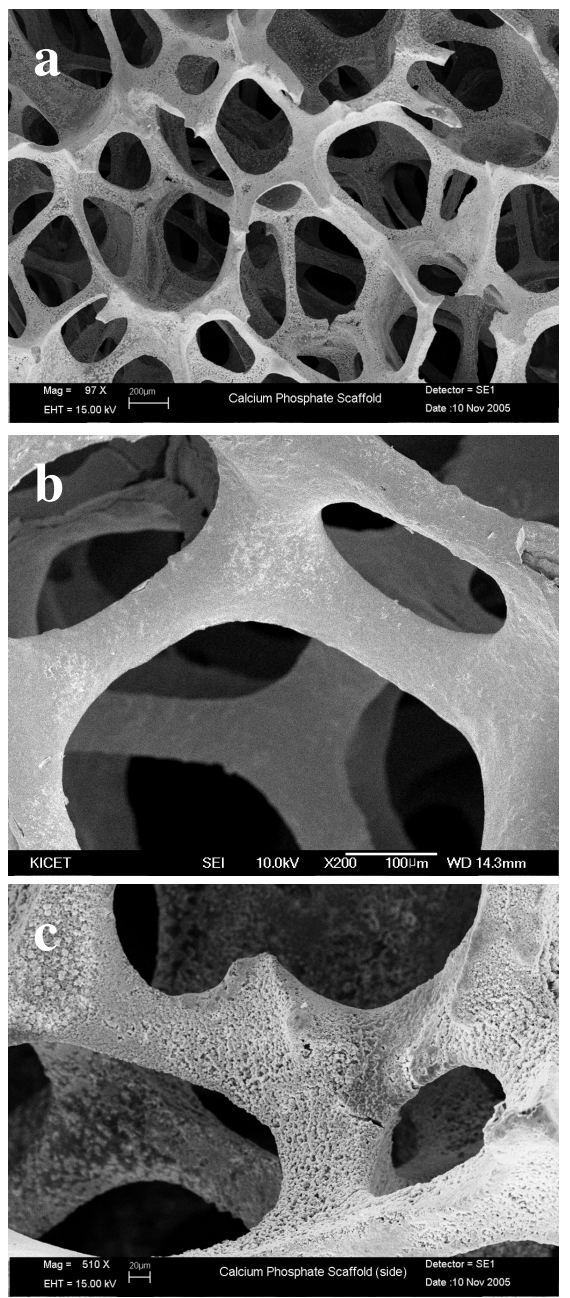

Fig. 2:Representative HA scaffolds showing (a) bulk architecture, (b) micro-crystalline surface, and (c) nano-crystalline surface.

\section{RECENT ADVANCES IN SYNTHESIS}

Friedman and co-workers have created a new tetracalcium phosphate that addresses the difficulties with malleability often encountered with the highporosity ceramics ${ }^{[42]}$. BoneSource ${ }^{\mathrm{TM}}$ is an HA that is supplied in powder-form. When it is mixed with sterile water, it has a paste-like consistency and setting the paste results in a microporous structure of 8-12 $\mu \mathrm{m}$. Despite its structure, BoneSource ${ }^{\mathrm{TM}}$ is rapidly adherent to bone and possesses the unique quality of direct conversion to new bone without loss of implant volume. This process of direct conversion has been termed osteoconversion ${ }^{[42]}$. With the aim of developing stronger ceramic scaffolds, Tomsia and co-workers have directed the freezing behavior of ceramic slurries to create a layered microstructure as much as four times the strength of traditional $50 \%$ porous HA implants ${ }^{[53]}$.

\section{IN VITRO CHARACTERISTICS}

3-D CaP scaffolds have a profound effect on the attachment and long-term survival of cells on a surface $^{[54]}$. As such, for specific cell types, there is an optimal pore topography that can be readily modulated by careful selection of the scaffold processing technique. Since bone has very different structures depending on its function and location, it stands to reason that the same pore shape may not be ideal for all potential uses. The scaffold influence on new bone formation, resorption rate, vascular infiltration, and mechanical integrity are just a few of the factors that ultimately determine implant success.

Osteoblast proliferation is sensitive to surface topography ${ }^{[55]}$, strain and other mechanical stimuli. It is known that contours of a material influence the differentiation of a host tissue. Particle size, shape, and surface roughness are also known to affect cellular adhesion, proliferation, and phenotype. Cells can discriminate even the subtlest changes in topography, and they are exceedingly sensitive to chemistry, surface roughness, and surface energy. Additionally, the surface energy may play a role in attracting particular proteins to the surface of the material and, in turn, this will affect the cells affinity to the material. Optimizing these surface features is particularly challenging with an absorbable material since the surface layer is in constant flux.

In addition to the direct cell-material interaction is the effect of biological environment on 3-D tissue cultures. Early optimization of scaffolds is often performed by in vitro tissue engineering. In the absence of a universal biomaterial or growth factor for skeletal regeneration, the development and improvement of cell culture techniques to mimic the in vivo environment becomes paramount. Tissue engineering strategies have allowed for improved screening of new candidate materials or modifications to existing designs. Bioreactors to perform fluid perfusion, mechanical strain and low intensity ultrasound are among the current techniques used to more closely simulate the natural bone environment and to meet the metabolic demands of large tissue-scaffold constructs. These systems contribute to the differentiation signals observed in the human body and stimulate a more natural tissue organization ${ }^{[44,56-58]}$. Highly porous HA scaffolds provide a framework for enhanced cell infiltration and migration throughout the scaffold. Cell spreading and proliferation with bone progenitors were capable of filling $400 \mu \mathrm{m}$ pores within two weeks. As shown in Fig. 3, scaffolds were filled with cells which began to regulate their own pore dimensions, leaving channels open for media flow, within one month of incubation. With the success of in 
vitro testing of these open scaffolds, further evaluation has been performed in animal models.
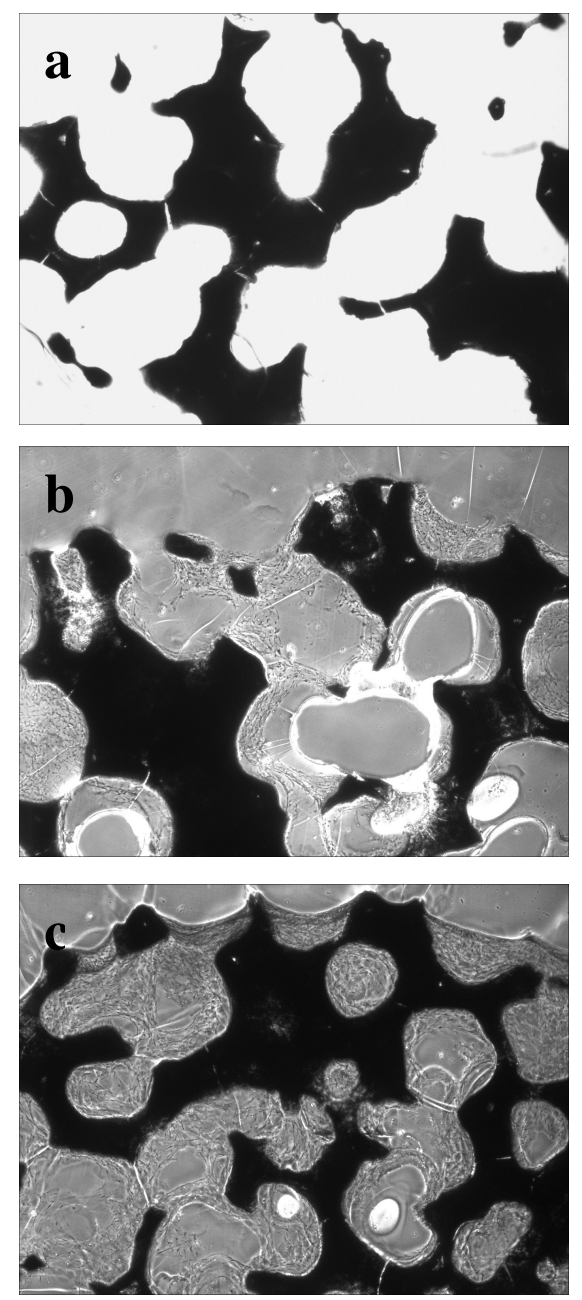

Fig. 3:Histology cross sections of (a) control scaffold, (b) scaffolds cultured with bone cell progenitors for two weeks, and (c) scaffolds cultured with bone cells for one month (image dimensions of $1.5 \mathrm{~mm}$ width $\mathrm{x} 1.1 \mathrm{~mm}$ height).

\section{IN VIVO CHARACTERISTICS / CLINICAL STUDIES}

The affect of pore size on cell behavior is also very cell-type specific. Gogolewski's laboratory reported that, although polyester membranes with pore size up to $200 \mu \mathrm{m}$ diameter promoted bone growth within a $1 \mathrm{~cm}$ defect of the radii of rabbits, smaller pore sizes promoted enhanced growth ${ }^{[59]}$. Tsurga and coworkers have suggested that the optimal pore size of ceramics that supports ectopic bone formation was 300-400 $\mu \mathrm{m}^{[60]}$. Holmes similarly suggested that the optimal pore range was $200-400 \mu \mathrm{m}$ with the average human osteon size of approximately $223 \mu \mathrm{m}^{[61]}$. Due to the necessity for proper capillary bed formation in successful implants, pore size greater than $300 \mu \mathrm{m}$ was recommended $^{[62]}$.
Porosity can, however, adversely affect important mechanical characteristics of a scaffold, requiring more complex material designs. The advantage of high porosity in scaffolds has been reported to achieve good cellular distribution, and that it is critical to select the correct pore size $^{[63]}$. For example, it has been reported that increased HA porosity decreases its malleability and reduces its ability to conform to the irregular surfaces that may be present in host bone ${ }^{[42,64-65]}$. This challenge may be overcome by re-engineering a porous $\mathrm{HA}$ to deliver bone inductive proteins such as recombinant human bone morphogenic protein 2 (rhBMP 2). This strategy has been reported to result in nearly uniform fixation, thereby allowing the authors to postulate that the porous HA acted as a conduit for the rhBMP induced growth of new bone allowing better fixation of the HA composite despite its porosity ${ }^{[66]}$.

In another study, osteoblastic cells in proximity to and on the ceramic at 14 days and 1 month were observed when block porous HA were implanted in rat femurs $^{[40]}$. Cytoplasmic processes of these osteoblasts appeared to deeply penetrate into the micropores of the ceramics. Although extensive in vivo studies have shown that porosity and pore size influences cell immigration, tissue in-growth, and tissue regeneration, there has been a general lack of appreciation for how the effects of composition, porosity and pore size on early cell activity may influence long term success ${ }^{[25-30 \text {, }}$ 67-74]

Other studies using larger animals, such as the implantation of porous, sintered HA in baboon muscles, have been reported to result in the induction of bone formation regulated by the substratum geometry ${ }^{[75]}$. It was further demonstrated that monolithic disks of sintered HA constructed with 400 and $1600 \mu \mathrm{m}$ concavities and implanted in the rectus abdominis of baboons resulted in bone generation exclusively in the concavities of the substratum. In addition, bone morphogenetic proteins (BMP) and osteogenic proteins were observed to be localized at the HA interface, suggesting that the geometry of the substrate, with the addition of BMP, may contribute to the osteoinductive characteristics of the HA substrate.

Precise control over surface features such as crystal size with the advent of nano-ceramic processing allows for scaffolds to improve their fusion with in vivo tissues. The potential of HA scaffolds with micro- and nano- based surfaces to demonstrate favorable results have also been tested in dog mandibular defect studies $^{[76-77]}$. From histological cross-sections, ingrowth of vascularized connective tissue and new bone was observed in micro and nano-crystalline scaffolds after 12 weeks post-operation (Fig. 4). The absence of significant bone regeneration can be seen in the control defect site, and appears more characteristic of trabecular bone. 

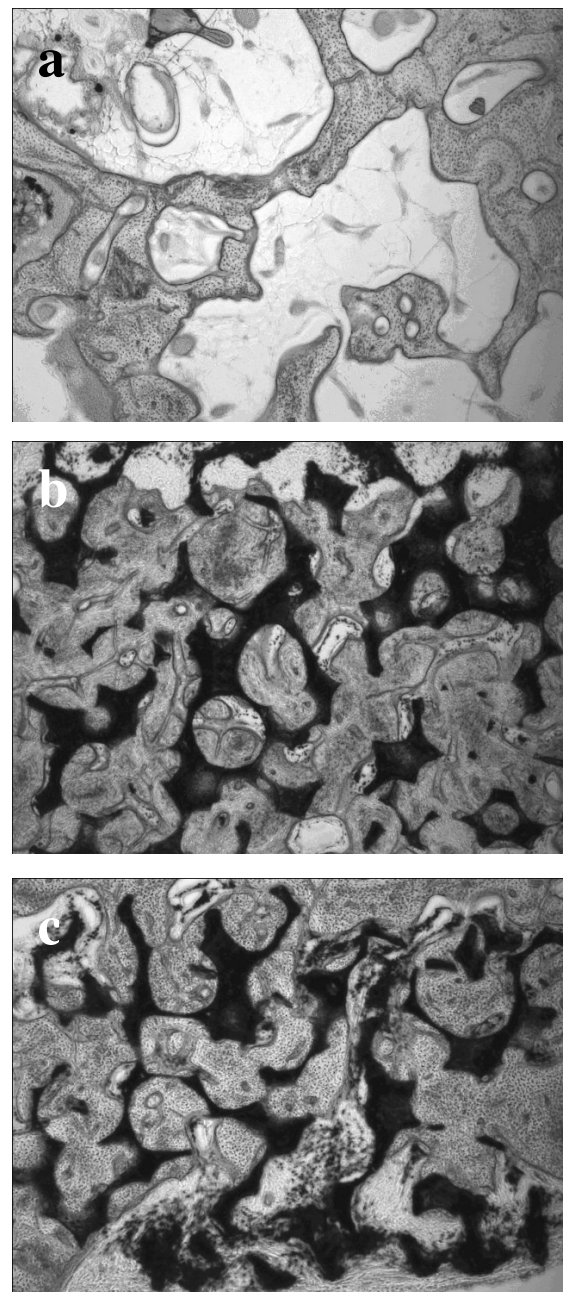

Fig. 4:Histology showing (a) defect site without scaffold, (b) new bone growth on HA scaffold with micro-crystalline surface after 12 weeks post-operation, and (c) new bone growth on HA scaffold with nano-crystalline surface after 12 weeks post-operation (Image dimensions of 2.9 $\mathrm{mm}$ width $\mathrm{x} 2.2 \mathrm{~mm}$ height).

As shown in Table 1, HA scaffolds with nanocrystalline surfaces exhibited statistically higher bone formation as compared to HA scaffolds with microcrystalline surfaces. Minimal new bone was observed for defects in the control group at weeks 3 and 6, and limited bone regenerated in the defects for the control group at week 12 .

Table 1: Evaluation of bone regeneration area after 12 weeks postoperation.

\begin{tabular}{lccc}
\hline & $\begin{array}{c}\text { Bone } \\
\text { Area }(\%)\end{array}$ & $\begin{array}{c}\text { Scaffold } \\
\text { Area (\%) }\end{array}$ & $\begin{array}{c}\text { Total } \\
\text { Porosity }(\%)\end{array}$ \\
\hline $\begin{array}{l}\text { Control } \\
\text { HA Scaffold with micro- } \\
\text { crystalline surface }\end{array}$ & $35.6 \pm 2.9$ & - & $64.4 \pm 2.9$ \\
$\begin{array}{l}\text { HA Scaffold with nano- } \\
\text { crystalline surface }\end{array}$ & $69.7 \pm 2.0$ & $22.6 \pm 1.8$ & $7.8 \pm 3.7$ \\
\hline
\end{tabular}

Clinically, Koshino et al inserted porous HA wedges into the tibias of 10 knees in 7 patients with osteoarthritis who underwent high tibial osteotomies. Histological examination at the time of hardware removal revealed pores located at the interface were completely filled with bone and depth of bone formation increased consistently with time ${ }^{[39]}$. In another study examining pore geometry and osteoconduction of porous HA implants placed in rabbit tibias, transverse sections demonstrated new bone growth through the pores. Osteon structure forming concentric lamellae around a single vessel in 50 and $100 \mu \mathrm{m}$ pore-sized cylindrical HA implants was observed at eight weeks. The same structures were observed around multiple vessels in the 300 and 500 $\mu \mathrm{m}$ pore-sized implants ${ }^{[78]}$. In addition, in a study of 103 patients with cranial defects in which BoneSource $^{\mathrm{TM}}$ was used, the success rate, which was based on maintenance of the implant and implant volume at 24 months, was approximately $97 \%{ }^{[42]}$.

\section{SUMMARY AND FUTURE AREAS OF DEVELOPMENT}

Substantial progress has been made in the analysis of progenitor cells with regard to differentiation pathways. This knowledge is being incorporated into the design of future scaffolds particularly with regard to optimization. Biomaterial development and final design will be essential to the appropriate stimulation and differentiation of bone cells. The environment in which these $\mathrm{CaP}$ tissue-scaffold systems are cultivated will greatly affect the long-term tissue viability. Furthermore, it will also be necessary to focus on creating the optimal micromechanical environment. Bioreactor studies examining the interaction of cellular systems with scaffold architectures continue in their developmental stage and may ultimately provide both a platform for improved cell-material science and a clinically relevant tissue bank for regenerative orthopedics.

Clinically, it is always of interest to improve methods of bone regeneration in order to reduce surgical trauma and expense to the patient. The ability to use autogenous bone forming cells attached to a mechanically sound, biologically active, and replaceable scaffolding would be ideal. This would allow implantation of the cellular scaffold without associated surgeries to harvest a graft or implant a static structural device. As a compromise, a similar cellular scaffold could be used in conjunction with conventional fixation techniques. However, the diverse nature and independent processing parameters of research in this field makes comparisons especially difficult and the need for consistency fundamental. As such, standardization will hopefully expedite the development of successful tissue-engineering alternatives. 


\section{REFERENCES}

1. Lanza, R., R. Langer, J.P. Vacanti, 1997. Principles of Tissue Engineering. R.G. Landes Company and Academic Press Inc., Texas, Austin.

2. http://www.epharmaceuticalnews.com/ tissue_engineering .html.

3. Bell, E., 1993. Tissue Engineering: Current Perspectives. Boston: Birkhauser, Boston, 1993.

4. Langer, R., J.P. Vacanti, 1993. Tissue Engineering. Science, 260: 920-926.

5. Healy, K.E., A. Rezania, R.A. Stile, 1999. Designing Biomaterials to Direct Biological Responses. Annals N.Y. Acad. Sci., 875: 24-35.

6. Service, R.F., 2000. Tissue Engineers Build New Bone. Science, 289:1498-1500.

7. Peppas, N.A., R. Langer, 1994. New Challenges in Biomaterials. Science, 263:1715-1720.

8. Lauffenburger, D.A., 1994. Cell Engineering. In: The Biomedical Engineering Handbook (ed. J.D. Bronzine) CRC Press, Boca Raton.

9. Kon, E., A. Muraglia, A. Corsi, P. Bianco, M. Marcacci, I. Martin, A. Boyde, I. Ruspantini I, P. Chistolini, M. Rocca, R. Giardino, R. Cancedda, R. Quarto, 2000. Autologous Bone Marrow Stromal Cells Loaded onto Porous Hydroxyapatite Ceramic Accelerate Bone Repair in Critical-size Defects of Sheep Long Bones. J. Biomed. Mater. Res., 49:328-337.

10. Gu, J., J. Xie, 2002. Experimental Study on Stimulation of Guided Bone Regeneration by Autogenous Bone Marrow. Chinese J. Reparative Reconst. Surg., 16:112-113.

11. Jie, Q., X. Dai, Q. Cao, 2002. Massive Allograft for Defects after Bone Malignant Tumor Resection. Chinese J. Modern Med., 12:60-62.

12. Lee, F.Y., E.J. Hazan, M.C. Gebhardt, H.J. Mankin, 2000. Experimental Model for Allograft Incorporation and Allograft Fracture Repair. J. Orthop. Res., 18:303-306.

13. Brown, K.L., R.L. Cruess, 1982. Bone and Cartilage Transplantation in Orthopaedic Surgery. J. Bone Jt. Surg. Am., 64-A:270-279.

14. Enneking, W.F., J.L. Eady, H. Burchardt, 1980. Autogenous Cortical Bone Grafts in the Reconstruction of Segmental Skeletal Defects. J. Bone. Jt. Surg. Am., 62-A:1039-1058.

15. Tian, J., Y. Zhang, C. Wang, X. Wang, X. Li, L. Zhang, Q. Ye, P. Ma, J. Chen, Z. Guo, 2002. Preparation and Design of Artificial Bone Scaffolds via a Three-dimensional Gel-lamination Process. Key Engineering Mater., 225:433-436.

16. Imai, S., K. Higashijima, A. Ishida, Y. Fukuoka, A. Hoshino, H. Minamitani, 2003. Determination of the Position and Orientation of Artificial Knee Implants using Markers Embedded in a Bone: Preliminary In Vitro Experiments. Med. Engineering and Physics, 25:419-424.
17. Sheng, L., G. Deng, X. Li, 2001. The Effects of Coral Artificial Bone Composite of Recombinant Human Bone Morphogenetic Protein-2 on Reconstruction of Extraction Sockets: An Experimental Study on Dogs. J. Jinan University, 22:75-79.

18. Sakai, T., S. Morita, K. Shinomiya, A. Watanabe, N. Nakabayashi, K. Ishihara, 2000. Prevention of Fibrous Layer Formation between Bone and Adhesive Bone Cement: In Vivo Evaluation of Bone Impregnation with 4-META/MMA-TBB Cement. J. Biomed. Mater. Res., 2000; 52:24-29.

19. Ishihara, S., T. Goshima, K. Kanekasu, A.J. Mcevily, 2002. The Static and Cyclic Strength of a Bone-cement Bond. J. Mater. Sci.: Mater. in Med., 13:449-455.

20. Gabbi, C., A. Cacchioli, B. Locardi, E. Guadagnino, 1995. Bioactive Glass Coating: Physichochemical Aspects and Biological Findings. Biomater., 16:515-520.

21. Okazaki, Y., 2002. Effect of Friction on Anodic Polarization Properties of Metallic Biomaterials. Biomater., 23:2071-2077.

22. Maehara, K., K. Doi, T. Matsushita, Y. Sasaki, 2002. Application of Vanadium-free Titanium Alloys to Artificial Hip Joints. Mater. Trans., 43:2936-2942.

23. Danesh-Meyer, M.J., U.M. Wikesjo, 2001. Gingival Recession Defects and Guided Tissue Regeneration: A Review. J. Periodont. Res., 36:341-354.

24. Agrawal, M., K.W. Koelling, J.J. Chalmers, 1998. Characterization of the Degradation of Polylactic Acid Polymer in a Solid Substrate Environment. Biotechnol. Prog., 14: 517-526.

25. Chu, C.R., A.Z. Monosov, D. Amiel, 1995. In Situ Assessment of Cell Viability within Biodegradable Polylactic Acid Polymer Matrices. Biomater., 16:1381-1384.

26. Agrawal, C.M., R.B. Ray, 2001. Biodegradable Polymeric Scaffolds for Musculoskeletal Tissue Eng. J. Biomed. Mater. Res., 55: 141-150.

27. Grad, S., L. Kupcsik, K. Gorna, S. Gogolewski, M. Alini, 2003. The Use of Biodegradable Polyurethane Scaffolds for Cartilage Tissue Engineering: Potential and Limitations. Biomater., 24: 5163-5171.

28. Lucke, A., J. Temmar, E. Schnell, G. Schmeer, A. Gopferich, 2000. Biodegradable Poly(D,L-lactic acid)- Poly(ethylene glycol)-monomethyl ether Diblock Copolymers: Structures and Surface Properties Relevant to Their Use as Biomaterials. Biomater., 21:2361-2370.

29. Ishaug-Riley, S.L., G.M. Crane-Kruger, M.J. Yaszemski, A.G. Mikos, 1998. Three-dimensional Culture of Rat Calvarial Osteoblasts in Porous Biodegradable Polymers. Biomater., 19:14051412. 
30. Trantolo, D.J., S.T. Sonis, B.M. Thompson, D.L. Wise, K.U. Lewandrowski, D.D. Hile, 2003. Evaluation of a Porous, Biodegradable Biopolymer Scaffold for Mandibular Reconstruction. Inter. J. Oral Maxillofac. Implants, 18:182-188.

31. Cima, L.G.., R. Langer, 1993. Engineering Human Tissue. Chem. Eng. Prog., 89: 46-54.

32. Lu, L., X. Zhu, R.G. Valenzuela, B.L. Currier, M.J. Yaszemski, 2001. Biodegradable Polymer Scaffolds for Cartilage Tissue Engineering. Clin. Orth. and Related Res., 391:251-270.

33. Tormala, P., J. Vasenius, J. Vainionpaa, J. Laiho, T. Pohjonen, P. Rokkanen, 1991. Ultra-highstrength Absorbable Self-reinforced Polyglycolide (SR-PGA) Composite Rods for Internal Fixation of Bone Fractures: In Vitro and In Vivo Study. J. Biomed. Mater. Res., 25:1-22.

34. Bostman, O.M., 1991. Current Concepts Review. Absorbable Implants for Fixation of Fractures. J. Bone Jt. Surg., 73A: 148-153.

35. Mooney, D.J., D.F. Baldwin, N.P. Suh, J.P. Vacanti, R. Langer, 1996. Novel Approach to Fabricate Porous Sponges of Poly(D,L-lactic-coglycolic acid) without the Use of Organic Solvents. Biomater., 17:1417-1422.

36. Chim, H., J.L. Ong, Jan-Thorsten Schantz, Dietmar W Hutmacher, C Mauli Agrawal. Efficacy of glow discharge gas plasma treatment as a surface modification process for three-dimensional poly (D,L-lactide) scaffolds. Journal of Biomedical Materials Research 2003, 65A[6]:327-335.

37. Sikavitsas, V.I., G.N. Bancroft, A.G. Mikos, 2001. Formation of Three Dimensional Marrow Stromal Cell-polymer Constructs in Bioreactors for Bone Tissue Engineering. Mater. Res. Symp. Proc., 662: LL1.2.1LL1.2.6.

38. White, E.W., E.V. Shors. Coated Biomaterials and Methods for Making Same, United States Patent, No. 4,976,736.

39. Mangano, C., E.G. Bartolucci, C. Mazzocco, 2003. A New Porous Hydroxyapatite for Promotion of Bone Regeneration in Maxillary Sinus Augmentation: Clinical and Histologic Study in Humans. Inter. J. Oral Maxillofac. Implants, 18:23-30.

40. Zyman, Z., I. Ivanov, V. Glushko, N. Dedukh, S. Malyshkina, 1998. Inorganic Phase Composition of Remineralisation in Porous CaP Ceramics. Biomater., 19:1269-1273.

41. Levine, J.P., J. Bradly, A.E. Turk, J.L. Ricci, J.J. Benedict, G. Steiner, M.T. Longaker, J.G. McCarthy, 1997. Bone Morphogenetic Protein Promotes Vascularization and Osteoinduction in Preformed Hydroxyapatite in the Rabbit. Ann. Plastic Surg., 39:158-168.

42. Freidman, C.D., P.D. Costantino, S. Takagi, L.C. Chow, 1998. BoneSource Hydroxyapatite Cement: A Novel Biomaterial for Craniofacial Skeletal Tissue Engineering and Reconstruction. J. Biomed. Mater. Res. (Appl. Biomater.), 43:428-432.
43. Hammerle, C.H., A.J. Olah, J. Schmid, L. Fluckiger, S. Gogolewski, J.R. Winkler, N.P. Lang, 1997. The Biological Effect of Natural Bone Mineral on Bone Neoformation on the Rabbit Skull. Clin. Oral Implants Res., 8:198-207.

44. Bouler, J.M., M. Trecant, J. Delecrin, J. Royer, N. Passuti, G. Daculsi, 1996; Macroporous Biphasic Calcium Phosphate Ceramics: Influence of Five Synthesis Parameters on Compressive Strength. J. Biomed. Mater. Res., 32:603-609.

45. Liu, D.M., 1997. Fabrication of Hydroxyapatite Ceramic with Controlled Porosity. J. Mater. Sci. Mater. Med., 8: 227-232.

46. Li, S.H., J.R. De Wijn, P. Layrolle, K. De Groot, 2002. Synthesis of Macroporous Hydroxyapatite Scaffolds for Bone Tissue Engineering. J. Biomed. Mater. Res., 61:109-120.

47. Chu, T.M., D.G. Orton, S.J. Hollister, S.E. Feinberg, J.W. Halloran, 2002. Mechanical and In Vivo Performance of Hydroxyapatite Implants with Controlled Architectures. Biomater., 23:12831293.

48. Padilla, S., J. Roman, M. Vallet-Regi, 2002. Synthesis of Porous Hydroxyapatites by Combination of Gelcasting and Foams Burn Out Methods. J. Mater. Sci. Mater. Med., 13:11931197.

49. Tian, J., J. Tian, 2001. Preparation of Porous Hydroxyapatite. J. Mater. Sci., 36:3061-3066.

50. Chang, B.S., C.K. Lee, K.S. Hong, H.J. Youn, H.S. Ryu, S.S. Chung, K.W. Park, 2000. Osteoconduction at Porous Hydroxyapatite with Various Pore Configurations. Biomater., 21:12911298.

51. Sepulveda, P., J.G.. Binner, S.O. Rogero, O.Z. Higa, J.C. Bressiani, 2000. Production of Porous Hydroxyapatite by the Gel-Casting of Foams and Cytotoxic Evaluation. J. Biomed. Mater. Res., 50:27-34.

52. Garg, R., R.K. Prud'homme, I.A. Aksay, 1997. 3D sterolithography of ceramic materials as orthopaedic implants. In: Biomaterials, Carriers for Drug Delivery, and Scaffolds for Tissue Engineering (eds N.A. Peppas, D.J. Mooney, A.G. Mikos, L. Brannon-Peppas) pp. 281-283. New York: AIChE, New York.

53. Deville, S., E. Saiz, R.K. Nalla, A.P. Tomsia, 2006. Freezing as a Path to Build Complex Composites. Science, 311:515-518.

54. Burg, K.J.L., A.G. Mikos, R.J. Beiler, C.R. Culberson, K.G. Greene, A.B. Loebsack, W.D. Roland, S. Wyatt, C.R. Halberstadt, W.D. Holder, Jr., T.C. Burg, 1999. Particulate selection and importance to cell adhesion in solvent-cast, particulate-leached polymeric constructs. In: Transaction of the $25^{\text {th }}$ Annual Meeting of the Society for Biomaterials, Providence, RI. 
55. Boyan, B.D., T.W. Hummert, D.D. Dean, Z. Schwartz, 1996. Role of Material Surfaces in Regulating Bone and Cartilage Cell Response. Biomaterials, 17:137-146.

56. Holtorf, H.L., N. Datta, J.A. Jansen, A.G. Mikos, 2005. Scaffold Mesh Size Affects the Osteoblastic Differentiation of Seeded Stromal Cells Cultured in a Flow Perfusion Reactor. J.Biomed. Mater. Res., 74A:171-180.

57. Kreke, M.R., A.S. Goldstein, 2004. Hydrodynamic Shear Stimulates Osteocalcin Expression but not Proliferation of Bone Marrow Stromal Cells. Tissue Eng., 10:780-788.

58. Di-Palma, F., A. Chamson, M.H. Lafage-Proust, P. Jouffray, O. Sabido, S. Peyroche, L. Vico, A. Rattner, 2004. Physiological Strains Remodel Extracellular Matrix and Cell-cell Adhesion in Osteoblastic Cells Cultured on Alumina-coated Titanium Alloy. Biomater., 25:2565-2575.

59. Pineda, L.M., M. Busing, R.P. Meinig, S. Gogolewski. 1996. Bone Regeneration with Resorbable Polymeric Membranes. III. Effect of Poly(L-lactide) Membrane Pore Size on the Bone Healing Process in Large Defects. J. Biomed. Mater. Res., 31:385-394.

60. Tsuruga, E., H. Takita, Y. Wakisaka, Y. Kuboki, 1997. Pore Size of Porous Hydoxyapatite as the Cell-substratum Controls BMP-induced Osteogenesis. J. Biochem., 121:317-324.

61. Holmes, R.E., 1979. Bone Regeneration within a Coralline Hydroxyapatite Implants. Plast. Reconstr. Surg., 63:626-633.

62. Karageorgiou, V., D. Kaplan, 2005. Porosity of 3D Biomaterial Scaffolds and Osteogenesis. Biomater., 27:5474-5491.

63. Solchaga, L.A., J.E. Dennis, V.M. Goldberg, A.I. Caplan, 1999. Hyaluronic Acid-base Polymers as Cell Carriers for Tissue-engineerined Repair of Bone and Cartilage. J. Orthop. Res., 17:205-213.

64. Koempel, J.A., B.S. Patt, K. O’Grady, J. Wozney, D.M. Toriumi, 1998. The Effect of Recombinant Human Bone Morphogenetic Protein-2 on the Integration of Porous Hydroxyapatite Implants with Bone. J. Biomed. Mater. Res., 41:359-363.

65. Tancred, D.C., B.A. McCormack, A.J. Carr, 1998. A Synthetic Bone Implant Macroscopically Identical to Cancellous Bone. Biomater., 19:23032311.

66. Linde, A., E. Hedner, 1995. Recombinant Bone Morphogenetic Protein-2 Enhances Bone Healing, Guided by Osteopromotive e-PTFE Membranes: An Experimental Study in Rats. Calcif. Tissue Int., 56:549-553.
67. Fu, K., D.W. Pack, A.M. Klibanov, R. Langer, 2000. Visual Evidence of Acidic Environment Within Degrading Poly(lactic-co-glycolic acid)(PLGA) Microspheres. Pharm. Res., 17:100106.

68. Qiu, Q.Q., P. Ducheyne, P.S. Ayyaswamy, 2002. Bioactive, Degradable Composite Microspheres: Effect of Filler Material on Surface Reactivity. Ann. N.Y. Acad. Sci., 974:556-564.

69. Friedenstein, A.J., Piatetzky-Shapiro, II, K.V. Petrakova, 1966. Osteogenesis in Transplants of Bone Marrow Cells. J. Embryol. Exp. Morphol. 1966; 16: 381-390.

70. Eggli, P.S., W. Muller, R.K. Schenk, 1988. Porous Hydroxyapatite and Tricalcium Phosphate Cylinders with Two Different Pore Size Ranges Implanted in Cancellous Bone of Rabbits. Clin. Orthopaed., 232: 127-138.

71. Klawitter, J., S. Hulbert, 1971. Application of Porous Ceramics for the Attachment of Load Bearing Orthopedic Application. J. Biomed. Mater. Res., 2: 161-167.

72. Flatley, T.L., K.L. Lynch, M. Benson, 1983. Tissue Response to Implants of Calcium Phosphate Ceramic in the Rabbit Spine. Clin. Orthop., 179: 246-252.

73. Bucholz, R.W., A. Carlton, R.E. Homlme. 1987. Hydroxyapatite and Tricalcium Phosphate Bone Graft Substitutes. Orthop. Clin., North Am., 18: 323-334.

74. Hollinger, J.C., G.C. Battistone, 1986. Biodegrable Bone Repair Materials: Synthetic Polymers and Ceramics. Clin. Orthop., 207: 290-305.

75. Ripamonti, U., 1996. Osteoinduction in Porous Hydroxyapatite Implanted in Heterotopic Sites of Different Animal Models. Biomater., 17:31-35.

76. Oh, S. N. Oh, M. Appleford, Y. Yang, J.L. Ong, 2006. Nano-coated calcium phosphate scaffolds for Bone regeneration in mandibular defect. In: Transaction of the $35^{\text {th }}$ Annual Meeting of the American Association for dental Research, Orlando, FL.

77. Oh, S., N. Oh, Y .Yang, M. Appleford, J. Bumgardner, W. Haggard, J.L. Ong, 2006. In-vivo evaluation of nano-coated calcium phosphate scaffolds for bone regeneration. In: Transaction of the $32^{\text {th }}$ Annual Meeting of the Society for Biomaterials, Pittsburgh, PN.

78. You, C.K., S.H. Oh, J.W. Kim, T.H. Choi, S.Y. Lee, S.Y. Kim SY, 2003. Hydroxyapatite Coated Porous Alumina as a New Orbital Implant. Key Eng. Mater., 240-242: 563-566. 